\title{
Study on Transportation Problem in Green Logistics
}

\author{
Cui Sun \\ School of Economic and Management \\ Shenyang Aerospace University \\ Shenyang, China
}

\author{
$\mathrm{Xu}$ Ying \\ School of Economic and Management \\ Shenyang Aerospace University \\ Shenyang, China
}

\begin{abstract}
By far, logistics has had more than 100-year development history since it was put forward by Johnsy Baker in 1905 in Troops and Transportation of Munitions. Most logistics mentioned by people in daily life are modern logistics which means a new-type integrated management combining all logistics activities such as information, transportation, storage, warehousing, handling as well as package and so on. In the west, logistics has been developed into a mature operative mode with wide development in practice as economic pillar and black house in service industry. The world industry has been turned to informatization from industrialization after experiencing industrial revolution, leading to today's green and sustainable development. With the increasingly more attention paid to greenhouse effect, the concept of low-carbon and sustainable development has also become more and more mature
\end{abstract}

Keywords- green logistics; green transportation; green transportation mode; green transportation strategy.

\section{INTRODUCTION}

Green transportation means that during the transportation, while controlling damage on environment caused by transportation, the transportation environment should be purified so as to make best use of transportation resources, which requires environmental symbiotic transportation system with improvement from the angle of environment. Green logistics aims to reduce environmental pollution and reduce resources consumption with a series of logistics activities process by adopting advanced logistics technology planning and implementation of transportation, storage, package, handling as well as distribution and processing. To make logistics green, each functional section during logistics should embody green and eliminate non-green factors; while for transportation, as the main means of creating spatial values by changing the spatial position of objects, it is the bridge connecting various sections such as production, allocation, distribution and consumption as well as the bond of communication among countries, regions and urban and rural areas, which is the decisive factor of logistics activity. Transportation plays a pivotal role in developing green logistics since logistics can be green if transportation realizes green transportation.

\section{THE PRINCIPLES FOR GREEN TRANSPORTATION}

\section{A. Principle of safety}

Safe transportation is the prior principle for green transportation including personal safety, equipment safety as well as goods safety. In order to ensure the safety of transportation, the goods properties should be first known such as the weight, volume, precious degree, internal structure as well as other physical or chemical properties to see if they are fragile, flammable, perishable and dangerous or not and then safe and reliable transportation means and tools can be selected, and special transportation tools can be adopted if necessary such as canister, refrigerated truck and so on. If the goods go bad during transportation with damage or safety accident, then more waste will be resulted with more serious environmental pollution

\section{B. Principle of timeliness and accuracy}

The timeliness of transportation means that goods should be delivered on time by customers' need; while the accuracy of transportation means that goods should be delivered on time correctly without wrong distribution or delivery. The turnover velocity of materials is determined by transportation speed as well as the delivery with great influence on the successful implementation of social reproduction. Customers will be in short of materials if the goods can't be delivered timely, and sometimes it can even bring losses to national economy. Therefore, transportation decisions should be made appropriately by customers' need. Although the accuracy of goods transportation depends on reception and distribution, it also has great relations to transportation means. For example, automobile can realize door-to-door service with less transit links as well as less accidents; while railway transportation can ensure timely delivery with little effect by objective environment.

\section{The united economic benefits and environmental benefits}

Transportation is one of the important components in logistics system and the improvement of logistics service level relies on high efficient transportation system, so improving economic benefits of 
transportation sub-system is also an important means to reduce logistics cost and increase profits. Therefore, the reduction of environmental pollution in transportation with better environmental performance should also be consistent with the goals of reduction of transportation cost and strengthening of competitive advantages, that is to say, environmental benefits should be unified with economic benefits

\section{Integral management of people and vehicles}

Here people refer to drivers specially since drivers are especially important for green transportation as important interface between enterprises and customers. The environmental awareness and responsibility of a driver can ensure the enforcement and implementation of a series of measures about reducing fuel consumption in enterprises. Drivers should be trained regarding environmental protection by including drivers' environmental management into enterprises' environmental management system so that drivers and vehicles can be integrated regarding environmental management.

\section{THE STRATEGIES AND MEANS FOR GREEN TRANSPORTATION}

\section{A. Technical progress will reduce environmental pollution}

\section{1) Develop and produce engines with more clean energy}

The reason why automobile transportation can produce serious air pollution is that automobiles are driven by petroleum products like petrol or diesel oil which can release hazardous substance while firing. Therefore, automobiles with alternative fuels such as methyl alcohol, ethyl alcohol, liquefied petroleum gas, compressed natural gas and so on should be encouraged. Besides, solar energy is also a clean energy, but it hasn't been popular since the technology is still immature. However, electric cars are transportation tools with mature technology at present which get rid of fuel engines but with airborne power. Some companies have tried using it. In addition, there are automobiles with hybrid power with drive system of both battery and fuel which can be altered by environment and road conditions.

2) Improve fuel utility rate and implement reduction technology of exhaust emissions

The vehicles' fuel consumption rate can be reduced with less air pollution by raising vehicles' fuel utility rate. Actually fuel consumption rate can be reduced by many technologies such as improvement of engine, control system and exhaust device as well as improvement of firing process and intake, exhaust and gas mixing process. Besides, the structure of engine and property of automotive aerodynamics can be improved so as to reduce fuel consumption and noise level. By promoting fuels with low sulfur and benzol and using diesel engine and electric motor with low sulfur emission, the urban pollution can be alleviated
It will improve traffic congestion, optimize driving route, promote transportation rate, guarantee traffic safety, and reduce energy consumption with obvious effect by developing intellectual traffic control system with computer technology, information technology and control technology.

4) Fuel consumption and management technology

In developed countries, they pay great attention to popularizing clean energy and clean-energy vehicles. Automobiles with clean energy have been encouraged to be developed and employed in American Clean Air Act as early as in 1990 with the formulation of more strict exhaust emission standard at the same time. In 1992, non-petroleum fuels were further encouraged in US Energy Policy Act.

While introducing new technology, drivers should be trained at the same time by giving rewards to drivers with excellent performance. When fuel usage is under monitoring, drivers will drive more carefully so as to reduce incidence of accidents with reduction of repair cost and insurance expenses.

\section{B. Training of vehicles' drivers and performance management}

Car driver is a key interface between logistics enterprise and customers. Broadly speaking, car driver is interface between logistics enterprise and public. Therefore, logistics enterprise should include drivers as well as their driving standards into corporate operation and management scope, consistent with management standards in other sections.

1)Drivers should be trained with fuel management knowledge related to drive and driving skills so as to master energy consumption method during driving with correct use of tire and accelerator and so on.

2)Drivers should be trained comprehensively on driving behaviors including strict compliance with traffic rules during driving by emphasizing on cultivation of sound habit of limited driving and so on

3)The fuel consumption situation during transportation can be recorded and inspected by appropriate information system software, and related information should be made public within enterprises by giving rewards to drivers with effective usage of fuels.

4)Direct communication can be realized with drivers by using remote communication system to monitor drivers' behaviors such as GPS and real-time data record which are beneficial to reduce energy consumption by drivers actively and to urge drivers to submit to enterprise policies and urban traffic act.

Training and management on drivers are beneficial to both enterprises and drivers. As for drivers, they can avoid traffic accidents by cultivating behavioral requirements of high standard and obeying speed limit rules so as to ensure self safety and health; while for enterprises, vehicles' consumption can be lowered by excellent drivers with lower transportation cost so as to avoid direct or indirect losses caused by accidents, leading to better enterprise performance. 


\section{Choose more environmentally friendly transportation means}

Compared to road transportation, railway transportation, waterway transportation and sea transportation have lower energy consumption with lower noise. But road transportation is still the only choice for many enterprises for its strong controllability, timeliness, flexibility, safety and low cost. If enterprises use railway transportation, sea transportation, and waterway transportation more frequently or combine these transportation means with road transportation, then it belongs to environmentally friendly transportation means.

1)By information exchanges and communication with customers, suppliers, other logistics enterprises, railway as well as multimodal professional enterprises, manufacturers and logistics enterprises can find new transportation means with comparison with current transportation means

2)When transportation distance is over 200 kilometers, then railway transportation can be considered to replace the crowded road transportation which is beneficial to reduce incidence of urban traffic accidents and establish cooperative partnership with other enterprises who have the same transportation start and ending so as to make the best use of train's carrying capacity with combined transportation among several enterprises.

3)When considering building new logistics facility site and new organizational system, we should ensure these new facilities close to railways and convenient for road transportation as possible as we can so that flexible business strategies are available for selecting transportation modes in the future, which is of great significance.

\section{Reduce usage of vehicles}

1) To combine transportation, ensure vehicles to drive fully loaded, and reduce dispatched times of vehicles

Drive under fully loaded can raise energy utility rate and reduce energy consumption of unit weight as well as reduce occupation of road by cargo of unit weight. Usually the professional distribution companies have extensive supply places and destinations, which can combine and distribute goods from different suppliers or have common distribution with other logistics enterprises to raise vehicles' loaded rate obviously and eliminate empty load phenomenon.

The transportation times can be obviously reduced by cooperating with components with better effect than cooperation with transportation partner alone.

Strategies of supplier can also reduce vehicles' driving miles and dispatched times. So suppliers should be encouraged to set supply station near important production plant so as to reduce transportation miles of procured raw materials effectively.

2) To optimize delivery route with the adoption of information system

Tollpost Global, a Norwegian company, participated in a project named "Greentrip" which is an environmentally friendly logistics transportation project facing to the whole world. The project team developed a logistics and transportation system based on computer, which integrates electronic map, customer information, cargo information, vehicle types as well as distribution location, delivery time schedule information, assisting the design of the shortest and the most effective driving route.

3) To raise one-time transportation quantity by improving package design and reducing package volume or weight

With the innovative package design scheme, usage times of vehicles can be reduced. In the countries with sound environmental laws, recycle and transportation of wrappage has become an important responsibility and duty of enterprises. Giving redesign of packaging ways from the perspective of better transportation is beneficial to all enterprises in the supply chain actually.

4) Equip with remote tracking system to offer route information

To link drivers' driving and transportation process with center computer network belongs to monitoring and information process after the arrangement of transportation plans; while the information system adopted above is used to make decisions and optimize routes. Tracking and monitoring of vehicles can help drivers to choose the most optimal route during transportation, which is also convenient for customers to know information about their cargo so as to raise customers satisfaction.

\section{E. Guarantee by government policies and regulations}

1) Formulate strict vehicle emission standard

Formulating vehicles' emission standard is kind of direct control. According to European experience, a set of strict emission control standards should be formulated to realize the goal of low pollution emission during transportation, including limitations on various vehicles' emissions. In addition, indirect control means should be adopted for the emission system of vehicles such as mandatory inspection and maintenance, mandatory usage of polluted vehicles and mandatory scrap on old vehicles.

\section{2) Provisions on fuel components}

Fuels with high contaminants should be restricted by laws and regulations, and they should be gradually stopped to be used by mandatory means, encouraging enterprises to update vehicles and eliminate old trucks in advance by using vehicles with clean energy

3) Formulate noise standards for vehicles

Some European countries have very strict standards for vehicles' noise. As early as in 1970, Britain has formulated noise standards for automobiles during manufacturing stage, during which noise from vehicles with over $200 \mathrm{hp}$ engine should not exceed 91 decibels. Besides, the newly manufactured automobiles in 1983 should meet more strict noise standards, that is, no more than 88 decibels with strict provisions on silencer and emission pipe on the vehicles. 
The driving routes should also be restricted by government. Vehicles with serious air pollution and noise pollution are forbidden to enter urban area where are crowded people. Exclusive lanes and priority should be given to buses; besides, buses should be equipped with air bag, drivers should wear seat belt, and driving speed should be restricted, all of which aim to reduce risks and accidents during transportation.

As for those who don't meet required demand should be punished strongly with common sanctions of legal means, administrative means and economic means so as to avoid continuous pollution to environment after being punished by enterprises

\section{4) Implement charges for pollution}

Polluters should pay for the pollution. According to economics principle, price reflects production and real social cost, which indicates that the real value of environmental service reflects in price rather than take it as free commodity. However, the payment should not be determined by waste emissions directly since drivers would adopt some special methods to deal with inspection with some extra fees for the inspection itself. We can realize the rational payment by taxation on automobiles. As for vehicles with serious pollution, they will be charged with more taxes, while environmentally friendly vehicles will be given more encouragement and support and even allowance

\section{5) Collecting tax on fuels}

Charging fuel tax is an effective method for emission and road users which is convenient for management and easy to be accepted by society, but the waste emissions are of great difference due to the different fuels. Fuel tax should be collected according to pollution degree. Fuels with serious pollution should be charged with more tax and eliminate them gradually by economic means; while for clean fuels, they should be given tax support. The most typical example is to collect tax on leaded gasoline. Almost all industrial countries are collecting taxes on leaded gasoline and Belguim even collected VAT on this kind of gasoline with $25 \%$ higher in 1990

\section{CONCLUSION}

With the two times of industrial revolutions, world economy has been developed rapidly, turning from rough-type economy into intensive economy with rational usage of resources so as to gain higher economic benefits. Since the Copenhagen Conference, people have paid more and more attention to green and low-carbon economy with a green trend all over the world. Under this circumstance, green logistics is complied with the times, which can be developed vigorously.

Transportation, as an important section of logistics, has significant role in promoting ecological environment of overall green logistics. The implementation of green transportation is the necessity of realizing sustainable development strategy. Sustainable development means that social economic development should be linked to natural environment and social environment so that economic construction can be coordinated with resources and environment to ensure a sound cycle of society. At present, economic development in our country is facing bottleneck due to environmental pollution. Some cities have serious air pollution, noise pollution and waste pollution; while some areas are short of water resources or have seriously polluted water; besides, some enterprises have low resources utility rate with serious waste. To build a harmonious society with implementation of sustainable development strategy requires governments at all levels and enterprises to assume social responsibilities during management, production and business activities so as to coordinate logistics activities with the development of natural environment and social environment so that logistics activities will be good for sound cycle of environment

\section{REFERENCES}

[1] China Logistics Development Report[R].2010-2011, China Logistics and Procurement Union, China Logistics Society

[2] Wang Lijun, Li Jianhong.Green Logistics Under Sustainable Strategy[J].Chinese Market.2007(32)

[3] Jiang Manyuan. Analysis on Means and Methods of Green Logistics and Transportation Based on Sustainable Development_- Taking Green Transportation in SHAPP Company As Example[J].Environmental Science and Management.2007(08)

[4] Liu Yanjun, Li Wensheng. Analysis on Problems Existing in Green Logistics Development in Our Country As Well As Countermeasures[J].Logistics Science and Technology.2007(07)

[5] Liya. Government's Role in Developing Green Logistics[J].Market Modernization.2010(01)

[6] Zhao Yiling. Economic Analysis on Backward Development of Green Logistics in Our Country As Well As Countermeasures[J].Logistics Engineering and Management.2010(01)

[7] Liuyang, Xin Lili. The Necessity of Developing Green Logistics Vigorously[J].Modern Economic Information.2008(09)

[8] Zhang Chunbo.Research on Current Green Logistics in Our Country As Well As Development Strategies[J]. Modern Commercial Industry.2010(05)

[9] Wang Xiaoxu. Research on Problems Existing in the Development of Green Logistics in Our Country As Well As Countermeasures[J].Logistics Science and Technology.2009(07)

[10] Feng Yuanmao, Fang Xiaoqiang, Cheng Honghai. Discussion on Problems Existing In Green Logistics Development in Our Country and Countermeasures[J].Construction of Old Area.2009(02)

[11] Xiong Wenjie. The Status Quo of Green Logistics Development As Well As Countermeasures[J].Chinese Market.2007(28)

[12] Li Chunxiang. To Improve Development of Green Logistics By Implementing Strategies of Green Transportation[J].Journals of Hunan Finance and Economics College.2008(05)

[13] S.A.H,Zahabi,L.MirandaMoreno,Z.Patterson,P.Barla,C.Harding.Transportation Greenhouse Gas Emissions and its Relationship with Urban Form,Transit Accessibility and Emerging Green Technologies: A Montreal case study.Procedia-Social and Behavioral Sciences[R],2012,(54):966-978.

[14] Tom Kreut. Prospects for producing low carbon transportation fuels from captured $\mathrm{C} 02$ in a climate constrained world. Energy Procedia[J], 2011, (4):2121-2128.

[15] Peter Headicar. Transport policy and planning in Great Britain. UK: Oxford Brookes University[R], UK, 2009. 